\title{
Heat transfer correlation for a triangular protruded surface with a cross-flow jet
}

\author{
POONAM PRUSTY, SWETAPADMA ROUT and ASHOK K BARIK*
}

Department of Mechanical Engineering, College of Engineering and Technology, Bhubaneswar 751029, India e-mail: ashokbarik.mech@gmail.com; ashok_iit@hotmail.com

MS received 31 May 2018; revised 14 February 2019; accepted 19 February 2019; published online 25 April 2019

\begin{abstract}
In this paper, the fluid flow and heat transfer characteristics of a small rectangular channel fitted with triangular protrusions have been studied in a three-dimensional computational domain. A hybrid cooling strategy employing forced convection air stream with jet impingement on the protruded surface has been numerically studied by solving the conservation equations for mass, momentum, energy as well as turbulent kinetic energy and its dissipation rate in the frame work of finite volume method. The duct and nozzle Reynolds numbers and Prandtl number are varied in the range of $17,827 \leq \operatorname{Re}_{D h, \text { duct }} \leq 53,480,5,135 \leq \operatorname{Re}_{D h, n z} \leq 12,044$ and $0.7 \leq \operatorname{Pr} \leq 12$, respectively. The effects of the duct Reynolds number, nozzle Reynolds number and Prandtl number on heat transfer rate have been quantified. Extensive numerical computation has also been executed to collect the data for Nusselt number by varying each of the independent parameters. A non-linear regression analysis based on Lvenberg-Marquardt ( $\mathrm{L}-\mathrm{M})$ method has been used to fit a correlation for Nusselt number utilizing the data captured from CFD analysis.
\end{abstract}

Keywords. Jet impingement; cross-flow; triangular protrusion; rectangular duct.

\section{Introduction}

Heat transfer enhancement from a rectangular duct with surface protrusions finds applications in various engineering fields such as solar air duct heaters, electronic cooling [1], gas turbine blade cooling [2], drying of textiles [3] to name a few. Effective and faster elimination of heat is inevitable in many miniaturized electronic devices in order to safeguard from excessive thermal load. The ever-increasing demand for the speed and longevity of the electronic as well as thermal equipment compel one to invent the better methods of cooling strategies. The convectional cooling strategies such as forced convection cooling and jet impingement cooling may not met the high heat dissipation standard set for these devices. In early days, the jet impingement heat transfer was thought as one of the better options for achieving a high heat transfer because of their high heat transfer coefficient in the impingement region. A great deal of research [4-12] has been devoted on jet impingement heat transfer investigating the effects of different parameters on heat transfer. However, the jet impingement method, in the context of miniaturization, may not be suitable to cool a substrate for high heat transfer applications. Also, the heat transfer enhancement in the field of renewable energy is another active area of research. The solar air duct heaters for various applications use

*For correspondence surface attachments to enhance the heat transfer. The heat transfer in a solar air duct with transverse ribs has been investigated by Boulemtafes et al [13]. The effect of transverse ribs on heat transfer rate as the function of different Reynolds number was demonstrated by them. For the solar air duct, Yadav and Bhagoria [14] numerically studied the effect of square transverse ribs on heat transfer rate. It has been reported by them that the heat transfer for the square ribbed duct was improved 2.86 times that of a smooth duct because of the transverse ribs. Jin et al [15] obtained a higher heat transfer rate for a solar absorber plate attached with multiple V-ribs, which are supposed to produce flow vortices leading to an intense fluid mixing. Other geometrical shape of protrusions such as rectangular, triangular, trapezoidal [16], $\mathrm{W}$-shaped [17, 18] and L-shaped [19] have been tested to enhance heat transfer rate. For a range of Reynolds number, Pandit et al [20] examined the heat transfer mechanism for an array of pin fins of different shapes (circular, triangular, hexagonal and diamond) mounted on the rectangular channel of a thermoelectric generator. The shape and ratio of the length of the pin-fin to channel height on heat transfer was investigated by them, and it was concluded that the diamond shaped pin-fin along with a low fin-length to channel-height ratio provide a better heat transfer rate. In some or all of the above works, heat transfer enhancement was carried out by employing surface protrusions either in laminar or mostly in turbulent regime. In some other methods of heat transfer 
enhancement, the surfaces were modified by installing turbulators and dimples. These surface fittings, in principle, improve the turbulence and increase the residence time of the coolant in the flow domain, which in turn, improves the mixing leading to an enhanced heat transfer rate. The literature on the heat transfer enhancement with dimples is abundant [21-28]. The surface protrusions/dimples/ribs increase the turbulence and disrupt the viscous sub-layer in the vicinity of the heated wall so as to impart a better mixing of the hot and cold fluid streams. Kumar et al [29] carried out an experimental investigation on the heat transfer rate and friction factor for heat exchanger with surface protrusions. They found that both the heat transfer rate and the friction factor are increased due to the protrusions. They also developed an empirical correlation for Nusselt number in terms of the pertinent parameters. In another experimental analysis, Gilani et al [30] showed that the staggered protrusions are better than the in-line protrusions. They also developed heat transfer coloration for Nusselt number. A good number of heat transfer correlations exist as far as heat transfer with dimples and protrusions is concerned. However, a few or none of these correlations utilize the combined effects of the convection, jet impingement and surface protrusions for the heat transfer enhancement from a heated surface. Recently, Barik et al [31, 32] studied the heat transfer enhancement from a rectangular duct by employing different shapes of surface protrusions (rectangular, triangular and trapezoidal), and taking air and alumina-water nanofluid as working fluid. They showed that the triangular protrusions were better heat transfer augmenter as compared to the other protrusion shapes. Although several studies have been carried out on the heat transfer augmentation, most of these studies concentrate on the heat transfer improvement either by the surface attachment or by the jet impingement. In the present study we have employed the combined effects of the forced convection, jet impingement as well as the surface protrusion to account the heat transfer enhancement from a heated surface.

\section{Physical model with grid}

The schematic diagram of the rectangular duct with triangular protrusions on bottom surface and an overhead impinging nozzle on the top surface has been depicted in figure 1. Four triangular protrusions have been used on the heated surface. To ensure a fully developed flow, an extra length of 10 times the hydraulic diameter has been taken ahead of the heated surface. Similarly, an extra length of 10 times the hydraulic diameter has been considered in the downstream of the heated surface so as to reduce the backflow at the outlet. All the walls except the bottom heated wall having the length of $X / D_{h, \text { duct }}=5.76$ (in the middle of the bottom surface) which is maintained at a constant temperature of $T=353 \mathrm{~K}$. The temperature of the heated surface resembles to the maximum operating temperature of an electronic chip. The grid arrangement and the different boundary conditions are shown in figure 2. The computational domain has been meshed with the hexahedral and tetrahedral meshes ensuring a hybrid meshing scheme. In the protruded region of the computational domain, tetrahedral meshes have been used because of the inclined surfaces of the triangular protrusions.

In order to have a better control over the number of cells in the computational domain, and to reduce the false diffusion, other regions are meshed with hexahedral cells. The working fluid (i.e., air) at a temperature $\mathrm{T}=300 \mathrm{~K}$ is allowed to flow through the inlet of the duct (main stream), and another stream of air at same temperature through the nozzle inlet impinges on the protruded surface to form a cross-flow arrangement with each other. The velocity inlet boundary conditions have been imposed on the duct and nozzle inlets. Uniform velocities are applied to these inlets. The pressure outlet boundary condition has been applied at the duct outlet as the fluid coming out of the outlet is flushed to the atmospheric condition. All walls except the isothermal heated surface are taken as adiabatic.

\section{Mathematical formulation}

\subsection{Governing differential equations}

Before writing the governing differential equations, different assumptions considered in this work are invoked as: (a) the working fluid (air) is taken as Newtonian and incompressible; (b) the flow is taken as three-dimensional, steady and turbulent; (c) the thermal conductivity $(\lambda)$, specific heat $\left(c_{p}\right)$ and dynamic viscosity $(\mu)$ of the fluid are kept constant. The Reynolds Averaged Navier Stokes (RANS) equations for mass, momentum, energy and turbulent kinetic energy $(k)$ and its dissipation rate $(\omega)$ are written in an inertial reference frame as follows:

$$
\begin{gathered}
\frac{\partial U_{i}}{\partial x_{i}}=0 \\
\rho U_{j} \frac{\partial U_{i}}{\partial x_{j}}=-\frac{\partial P}{\partial x_{i}}+\frac{\partial}{\partial x_{j}}\left(2 \mu S_{i j}-\rho \overline{u_{i}^{\prime} u_{j}^{\prime}}\right) \\
\rho U_{j} \frac{\partial T}{\partial x_{j}}=\frac{\partial}{\partial x_{j}}\left(\frac{\lambda}{c_{p}} \frac{\partial T}{\partial x_{j}}-\rho \overline{u_{i}^{\prime} T^{\prime}}\right) \\
\text { The mean strain rate, } S_{i j}=\frac{1}{2}\left(\frac{\partial U_{i}}{\partial x_{j}}+\frac{\partial U_{j}}{\partial x_{i}}\right)
\end{gathered}
$$

$\mu, \lambda$ and $c_{p}$ are the dynamic viscosity, thermal conductivity and specific heat of the working fluid. The mean velocity, pressure and temperature are denoted as $U, P$ and $T$, respectively. The turbulent Reynolds stress $\left(-\rho \overline{u_{i}^{\prime} u_{i}^{\prime}}\right)$ and 


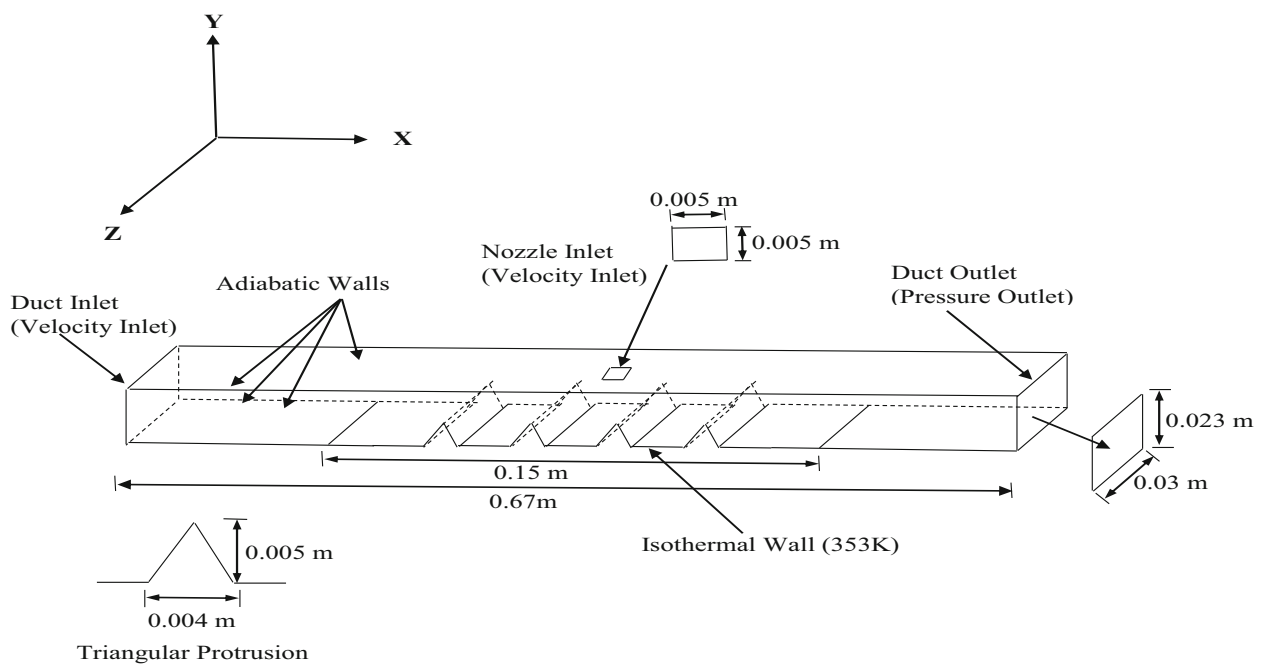

Figure 1. Physical geometry.

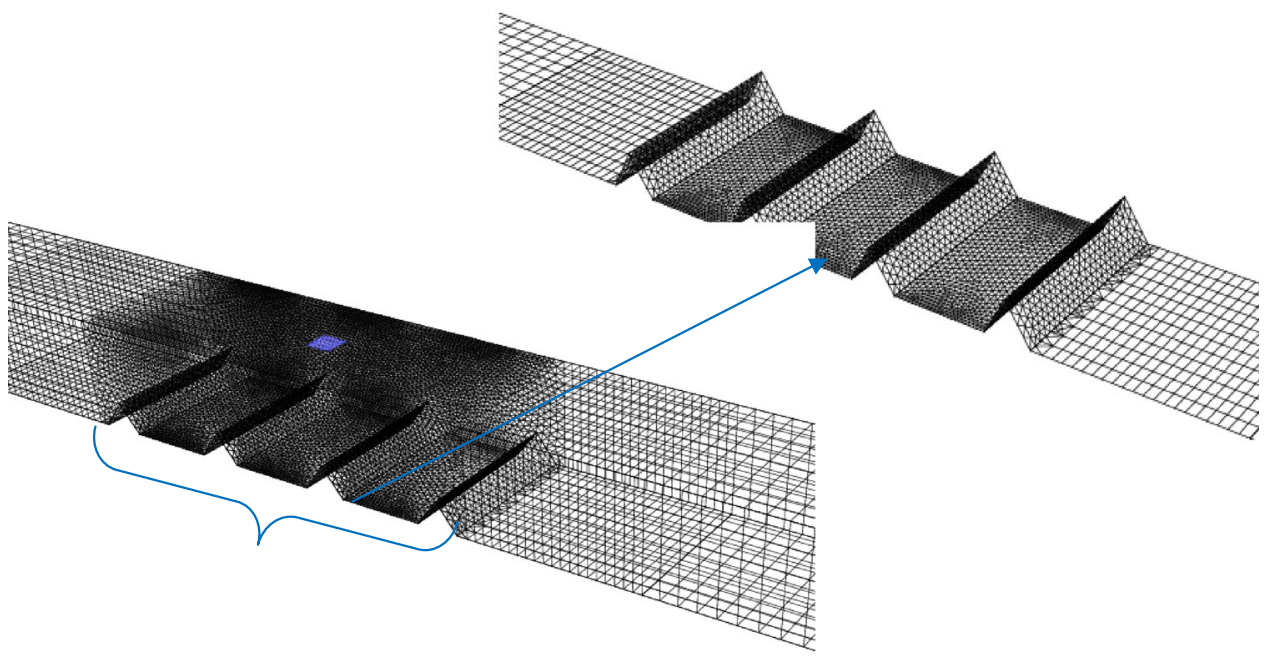

Figure 2. Exploded view of the grid arrangement.

heat flux $\left(-\rho \overline{u_{i}^{\prime} T^{\prime}}\right)$ are obtained from RANS equations and these quantities are to be closed by using a suitable turbulence model. The Reynolds stress appearing in Eq. (2) is modelled by using a linear eddy viscosity model via the mean strain rate $\left(S_{i j}\right)$, turbulent kinetic energy $(k)$ and eddy viscosity $\left(\mu_{t}\right)$ as

$$
-\rho \overline{u_{i}^{\prime} u_{i}^{\prime}}=2 \mu_{t} S_{i j}-\frac{2}{3} \rho k \delta_{i j}
$$

The turbulent kinetic energy and its dissipation rate are obtained in the computational domain by incorporating the SST $k-\omega$ model as has been proposed by Menter [33]. Similarly, the turbulent heat flux is defined as $-\rho \overline{u_{i}^{\prime} T^{\prime}}=\frac{\mu_{t}}{\operatorname{Pr}_{t}} \frac{\partial \bar{T}}{\partial x_{i}}$, where $\operatorname{Pr}_{t}$ denotes the turbulent Prandtl number. The governing equations for turbulent kinetic energy and its dissipation rate are written as follows:

$$
\begin{aligned}
\frac{\partial}{\partial x_{i}}\left(\rho k U_{i}\right)= & \frac{\partial}{\partial x_{j}}\left[\left(\mu+\frac{\mu_{t}}{\sigma_{k}}\right) \frac{\partial k}{\partial x_{j}}\right]+\min \left(p_{k}, 10 \rho \beta^{*} k \omega\right) \\
& -\rho \beta^{*} k \omega \\
\frac{\partial}{\partial x_{i}}\left(\rho \omega U_{i}\right)= & \frac{\partial}{\partial x_{j}}\left[\left(\mu+\frac{\mu_{t}}{\sigma_{k}}\right) \frac{\partial \omega}{\partial x_{j}}\right]+\frac{\alpha \omega}{k} p_{k}-\rho \beta \omega^{2} \\
& +2\left(1-F_{1}\right) \frac{\rho \sigma_{\omega, 2}}{\omega} \frac{\partial k}{\partial x_{j}} \frac{\partial \omega}{\partial x_{j}}
\end{aligned}
$$

The turbulent viscosity/eddy viscosity is modelled as : $\mu_{t}$

$$
=\rho \frac{k}{\omega} \frac{1}{\max \left(\frac{1}{\alpha^{*}}, \frac{S F_{2}}{a_{1} \omega}\right)}
$$


Where the modulus of mean strain rate tensor, $S=\sqrt{2 S_{i j} S_{i j}}$. In SST $k-\omega$ model the turbulent viscosity is modelled by using a damping coefficient $\alpha^{*}$, which is written as:

$$
\alpha^{*}=\alpha_{0}^{*}\left(\frac{\alpha_{0}^{*}+\frac{\mathrm{Re}_{\mathrm{t}}}{R_{k}}}{1+\frac{\mathrm{Re}_{\mathrm{t}}}{R_{k}}}\right)
$$

Where $\alpha_{0}^{*}=\frac{\beta_{i}}{3}$ and $\operatorname{Re}_{t}=\frac{\rho k}{\mu \omega}$. The blending functions $F_{1}$ and $F_{2}$ are defined as: $F_{1}=\tanh \left(\varphi_{1}^{4}\right)$ and $F_{2}=\tanh \left(\varphi_{2}^{2}\right)$, respectively. The values of $\varphi_{1}$ and $\varphi_{2}$ are computed as follows: $\varphi_{1}=\min \left(\max \left(\frac{k}{0.09 \omega y}, \frac{500}{\rho y^{2} \omega}\right), \frac{4 \rho k}{\sigma_{\omega, 2} D^{+} y^{2}}\right)$ and $\varphi_{2}=$ $\max \left(2 \frac{\sqrt{k}}{0.09 \omega y}, \frac{500 \mu}{\rho y^{2} \omega}\right)$, respectively. The distance to the next surface is represented as $y$ in the above two expressions. The positive portion of the cross-diffusion is defined as: $D_{\omega}^{+}=\max \left(\frac{\rho}{\sigma_{\omega, 2} \omega} \frac{\partial k}{\partial x_{j}} \frac{\partial \omega}{\partial x_{j}}, 10^{-10}\right)$. The production of the turbulent kinetic energy is expressed as: $p_{k}=-\rho \rho \overline{u_{i}^{\prime} u_{j}^{\prime}} \frac{\partial U_{i}}{\partial x_{j}}$. The term $\beta^{*}$ appeared in Eq. (10) is equal to $\beta_{i}^{*}$, and is defined as:

$$
\beta_{i}^{*}=\beta_{\infty}^{*}\left(\frac{4 / 15+\left(\mathrm{Re}_{\mathrm{t}} / \mathrm{R}_{\beta}\right)^{4}}{1+\left(\mathrm{Re}_{t} / R_{\beta}\right)^{4}}\right)
$$

Generally, the flow past an obstacle is unsteady due to the presence of wakes generated due to flow recirculation. The unsteadiness is more severe while simulating a thermal buoyant plume [34, 35] past an obstacle at high Rayleigh number. For such flows it is always preferred to use unsteady RANS (U-RANS) instead of steady RANS (SRANS), and the U-RANS would be one of the better choices for quantifying the mean quantities, especially the prediction of normal and shear stresses [36, 37]. But in our case, the mean flow is grossly steady and the small regions (in between protrusions) near the protruded surface show the flow recirculation and are unsteady. The flow, in the present situation, is steady in a quite large portion of the domain which receives the fluid through the inlets and flushes through the outlet. Hence, the mean flow quantities, especially, the time averaged velocities are steady. Therefore, we used the S-RANS instead of U-RANS.

As SST $k-\omega$ model [33] incorporates the cross-diffusion term and damping coefficient, this model can predict the flow phenomenon in a more accurate manner as compared to the simple $k-\varepsilon$ model. In the present study, we expect a strong flow separation and reattachment due to the presence of protrusions, and this circulatory flow features may not be predicted by $k-\varepsilon$ model. Therefore, we preferred to use the SST $k-\omega$ model. Different model constants used in SST turbulence model are given as follows:

$$
\begin{aligned}
\alpha_{\infty}^{*} & =1, \beta^{*}=0.09, \beta_{i}=0.072, \sigma_{\omega, 2}=1.168, \sigma_{\omega, 1}=2, \sigma_{k, 1} \\
& =1.176, R_{k}=6, a_{1}=0.31 \text { and } R_{\beta}=8
\end{aligned}
$$

The heat transfer coefficient is computed as, $h$

$$
\begin{gathered}
=\frac{Q}{A_{\text {total }}\left(T_{w}-T_{m}\right)} \\
T_{m}=\frac{1}{A_{\text {total }}} \int T d A \\
A_{\text {total }}=A_{b w}+A_{P}
\end{gathered}
$$

The total area $\left(A_{\text {total }}\right)$ is the sum of the bare area of the heated surface $\left(A_{b w}\right)$ and area of the surface protrusions $\left(A_{P}\right)$.

$$
\text { The local Nusselt number is computed as: } N u=\frac{h L}{\lambda}
$$

$$
\begin{aligned}
& \text { The average Nusselt number is calculated as }: \overline{N u} \\
& =\int_{A_{\text {total }}} N u d A
\end{aligned}
$$

\section{Numerical solution procedure}

Conservation equations for mass, momentum, energy, turbulent kinetic energy $(\mathrm{k})$ and its dissipation rate $(\omega)$ are solved using finite volume method of the commercial software ANSYS Fluent R16. First the computational domain is discretized into a large number of discrete and small control volumes, and then numerical integrations are performed to yield a set of algebraic equations. These equations are solved iteratively by applying suitable boundary conditions on the entire bounding surfaces due to the elliptic nature of the governing equations. The whole field residual method of the ANSYS Fluent R16 solver is used to solve these equations iteratively. To achieve a better accuracy in the solution, the diffusion terms have been discretised using central difference schemes. However, the advection terms are discretized using the 2nd order upwind scheme in order to keep the false diffusion [38] at a minimum level. Both the $2^{\text {nd }}$ order central difference and the upwind schemes are $2^{\text {nd }}$ order accurate. So, one can get a better result with $2^{\text {nd }}$ order scheme as compared to the $1^{\text {st }}$ order scheme. Since in the present case the flow is incompressible, a segregated and pressure based solver is used to solve the equations. The pressure-velocity coupling has been established using the SIMPLE method of Patankar [39]. The solution is progressed until the error falls below the user supplied underrelaxations. The under-relaxation factors for momentum, energy as well as the turbulence equations are taken as: 0.7, 0.8 , and 0.5 (both for turbulent kinetic energy and its dissipation rate), respectively. The iterative solutions of the governing equations are declared converged if the residuals for all the equations fall below $10^{-4}$, except the energy equation. The convergence criterion for energy equation is taken as $10^{-7}$. 


\section{Boundary conditions}

The graphical presentation of the numerical boundary conditions has been depicted in figure 1 . The inlets for the duct and nozzle, through which the working fluid enters the computational domain with uniform velocity, are applied to the velocity inlet boundary condition. For an incompressible flow with known velocity at inlets, the velocity inlet boundary condition is usually preferred over the mass flow inlet condition. At the outlet, the pressure outlet boundary condition has been invoked as the flow issues to ambient pressure and temperature conditions. The top and side walls are imposed to the adiabatic boundary conditions. The bottom wall except the isothermal wall with surface protrusions is applied to the adiabatic boundary condition. A constant temperature of $T=353 \mathrm{~K}$ is applied to the heated wall which is practically the maximum operating temperature of an electronic chip. The solution variables near-wall cells have been linked to the corresponding variables on the wall via the standard wall function of Launder and Spalding [40]. The law-of-wall for mean velocity is given as:

$$
\begin{gathered}
\frac{U_{p} k_{p}^{1 / 2} c_{\mu}^{1 / 4}}{\tau_{w} / \rho}=1 / \kappa \operatorname{In}\left(E y^{*}\right) \\
y^{*}=\frac{\rho k_{p}^{1 / 2} c_{\mu}^{1 / 4} y_{p}}{\mu}
\end{gathered}
$$

In Eq. (16), $E, \kappa$ denote the empirical and von Karman constants equal to 9.793 and 0.4187 .

The mean velocity of fluid at a point ' $\mathrm{p}$ ' is denoted as $U_{p}$. The turbulent intensities at duct and nozzle inlets are computed as $I=0.016 \operatorname{Re}^{-1 / 8}$, where $\operatorname{Re}=\operatorname{Re}_{D h \text {,duct }}$ or $\operatorname{Re}=\operatorname{Re}_{n z}$, respectively. The viscosity ratio at both the inlet and outlet are taken as $10 \%$. The mathematical forms of the boundary conditions are given as:

$$
\begin{aligned}
& \text { Adiabatic walls: } U=V=W=0, \frac{\partial T}{\partial x}=\frac{\partial T}{\partial y}=\frac{\partial T}{\partial z}=0 \\
& \text { Hot wall: } U=V=W=0, \quad T=T_{w}=353 \mathrm{~K} \\
& \text { Duct inlet: } U=U_{i n}, V=W=0, T=300 \mathrm{~K} \\
& \text { Nozzle inlet: } V=-V_{i n}, U=W=0 \text { and } T=300 \mathrm{~K}
\end{aligned}
$$

Here $U, V$ and $W$ are the velocity components in the $\mathrm{x}, \mathrm{y}$, and $\mathrm{z}$ - direction, respectively.

$$
\text { Duct outlet: } P=0 \text { (Gauge pressure) }
$$

It is worth to mention here that the standard wall function gives a reasonable accuracy for wall bounded and high Reynolds number flows. But this wall function has some disadvantages for flows having a strong buoyancy effect, wall transpiration, and the flow rotation with adverse pressure gradient. In our case, flow is bounded by the walls and flow is mainly forced convection. The flow-rotation is seen behind the protrusions, and there is negligible or no flow rotation in most of the regions of computational domain. Therefore, standard wall function may be a good option to link the bulk flow quantities with those of the first cells near the wall. As our prime concern of in this work is to develop a correlation for Nusselt number in terms of different parameters those influence the flow field, so it is thought that the standard wall function would be good choice without incurring gross inaccuracy in the computed results.

\section{Validation}

The available literature on the cross-flow jet impingement on a protruded surface is sparse. There exists abundant literature on thermo-fluid characteristics of jet impingement heat transfer. The present numerical code has been validated with the experimental [41] and the empirical Nusselt number published in previous literature $[42,43]$ elsewhere. To validate our results, a circular heated plate of diameter $46 \mathrm{~mm}$ has been used. The constant heat flux applied to this plate is calculated implicitly using experimental data outlined in [41]. The jet diameter to plate ratio is kept one as has been mentioned in [41]. The diameter of the nozzle is taken as 4 $\mathrm{mm}$. Several grids staring from the coarse one to fine (i.e., initially 16,000 hex mesh) have been used. The final computation was carried out with 57,000 cells in the computational domain. The SST $k-\omega$ turbulence model has been used to model the turbulence quantities. A detailed discussion of this model is given elsewhere in this paper. The top wall of the domain is confined and adiabatic. The duct outlet is imposed to the pressure outlet boundary condition. The present validation has been chosen as an isothermal jet impinges to the heated wall, and the situation is almost similar to our present study. The stagnation point Nusselt number has been computed through ANSYS Fluent R16, and the comparison of these results is shown in figure 3.

Also, in the same plot, we have compared the Nusselt number obtained from the correlation equations given in $[42,43]$. It has been observed that the present numerical method predicts the Nusselt number quite well as compared to the results given in [41-43]. It is worth to mention here that our numerical procedure matches quite well with Choo and Kim [42] results with a maximum error of $1.2 \%$. Similarly, when our results are compared with the results of Markel and Aydin [41], the error obtained is only 4.24\%. But the maximum error introduced by our numerical is about $5.1 \%$ when it is compared to the correlation of Lytel and Webb [43]. From the above discussion, we thus, derived the confidence to use the present numerical method in our present study. 


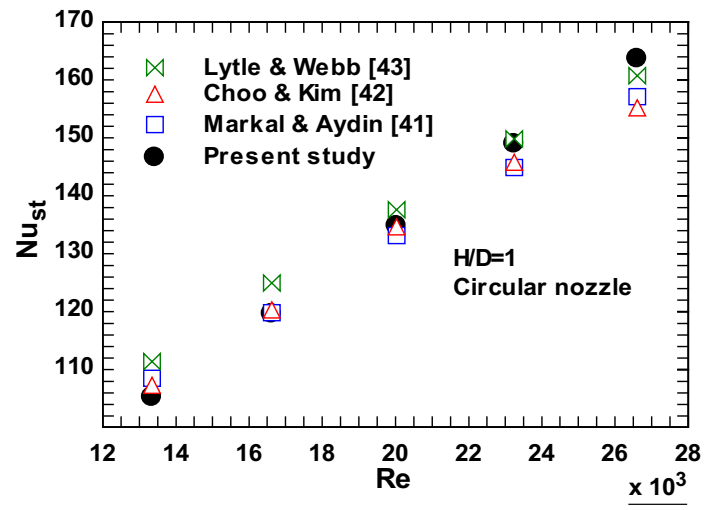

Figure 3. Variation of $N u_{\text {st }}$ with Re.

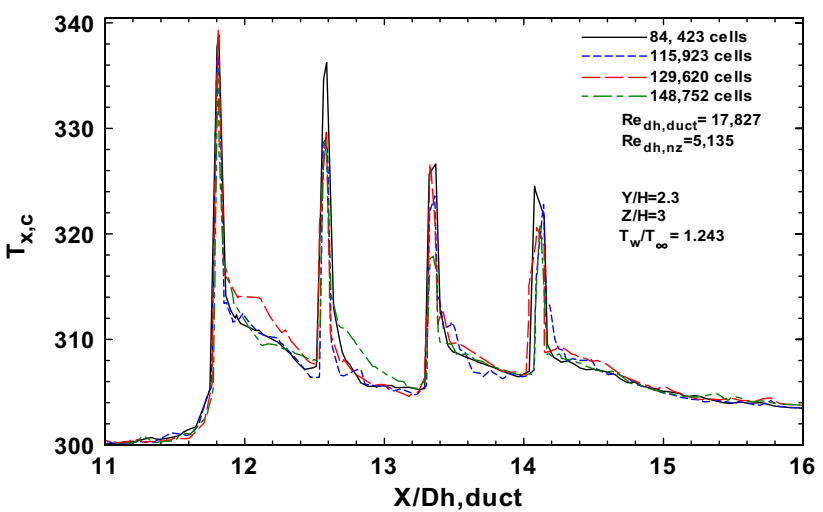

(a)

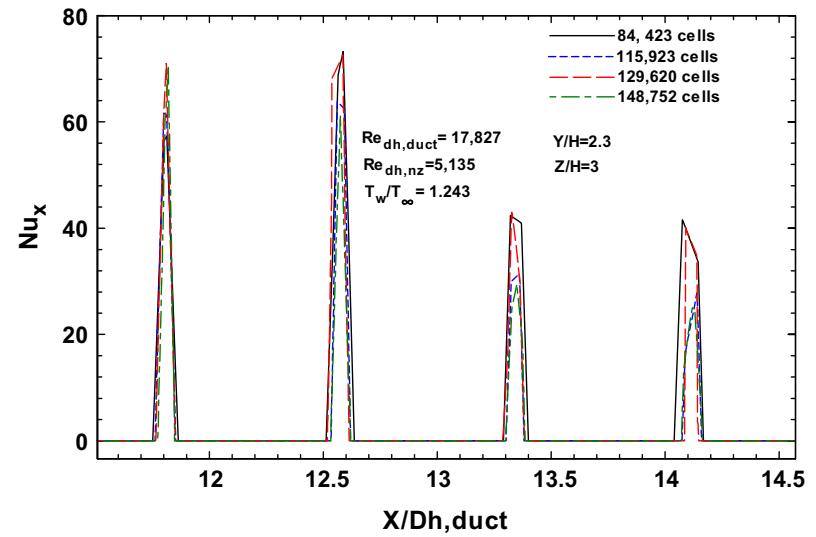

(b)

Figure 4. Variation of (a) Centerline temperature. (b) Local Nusselt number with axial distance.

\section{Grid independence test}

The grid independence test for the present study has been shown in figure 4(a) and (b). To test grid independence of the solution variables, four different meshes of grid numbers of $84,423,115,923,129,620$ and 148, 752 have been taken into the consideration. The centerline temperatures for all the above mentioned meshes are plotted against the axial distance in figure 4(a). The other simulation conditions have been shown in figure 4(a). The change in the center line temperature as well as the local Nusselt number (shown in figure 4(b)) is almost negligible after 129, 620 cells. Thus, this domain has been taken for our further investigation.

\section{Results and discussions}

\subsection{Effect of $\operatorname{Re}_{D h, \text { duct }}$ and $\operatorname{Re}_{D h, n z}$ number on heat transfer}

The present investigation begins with the effect of duct Reynolds number on the heat transfer enhancement. Figure 5(a) illustrates the effect of duct Reynolds number on the Nusselt number at different nozzle Reynolds numbers. It can be seen that the average Nusselt number increases monotonously with the duct Reynolds number irrespective of the nozzle Reynolds number. The increase in the average Nusselt number is because of an enhanced convection at a high Reynolds number, which can carry more heat from the heated surface. At a particular $\operatorname{Re}_{D h, n z}=5,134$ and over the entire range of the duct Reynolds number (i.e., $17,827 \leq \operatorname{Re}_{D h \text {,duct }} \leq 53,480$ ), it has been observed that the Nusselt number increases $102.57 \%$ as the duct Reynolds number increases from 17,827 to 53,480 . For other nozzle Reynolds numbers, similar trends have also been noticed. The large heat transfer rate at a high duct Reynolds number could be the enhanced turbulent kinetic energy inside the fluid domain due to the increased momentum of the main stream.

Figure 5(b) shows the evolution of the centerline turbulent kinetic energy with the axial distance as the function of duct Reynolds number $\left(\operatorname{Re}_{D h, d u c t}\right)$. A more turbulent kinetic energy has been produced in the domain at a high duct Reynolds number. At $\operatorname{Re}_{D h \text {.duct }}=53,480$, the turbulent kinetic energy (TKE) is found to be the highest among all other Reynolds numbers as shown in figure 5(b). Since the turbulence imparts a better mixing of the hot and cold streams of fluids, so the heat transfer rate is enhanced. Two distinct peaks in TKE have been observed; the first one is due to the hitting of the main stream with the first protrusion, and the second one is because of the jet impingement of the nozzle fluid on the main stream. Furthermore at particular duct Reynolds number, the Nusselt number increases marginally which perhaps due to the blowing off of the nozzle fluid along with the high momentum main fluid. Therefore, the relatively low momentum nozzle stream is not able to reach to the heated surface so as to enhance the heat transfer. But it could be seen from figure 5(a) that the Nusselt number also increases with the nozzle Reynolds number for a particular duct Reynolds number. Although we have varied nozzle Reynolds number from 5,135 to 12,044 , we see a very little increment in Nusselt number with the nozzle Reynolds number, and the 


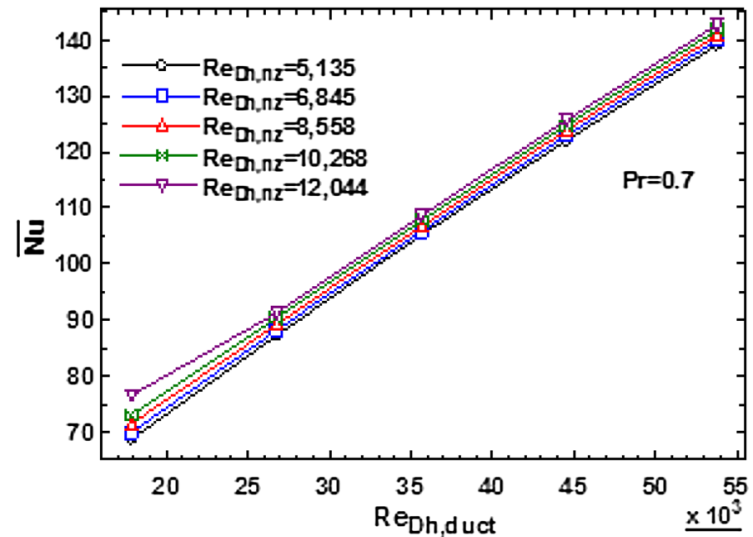

(a)

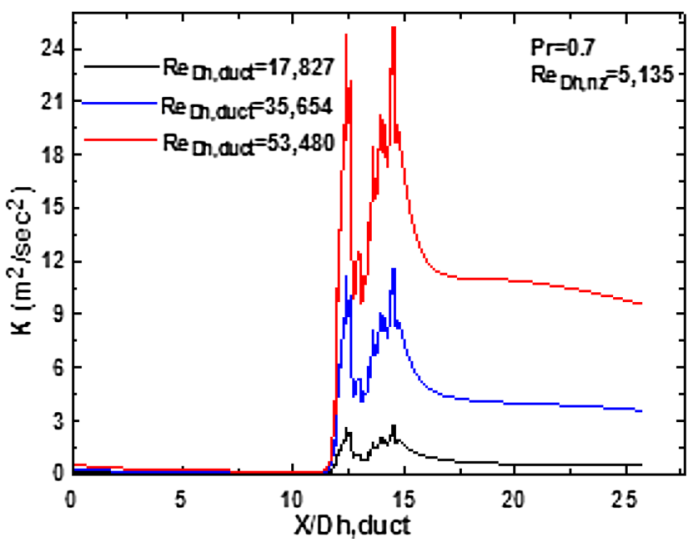

(b)

Figure 5. (a) Variation of $\operatorname{Re}_{D h, d u c t}$ on $\overline{N u}$ as a function of $\operatorname{Re}_{D h, n z}$. (b) Centreline TKE evolution.

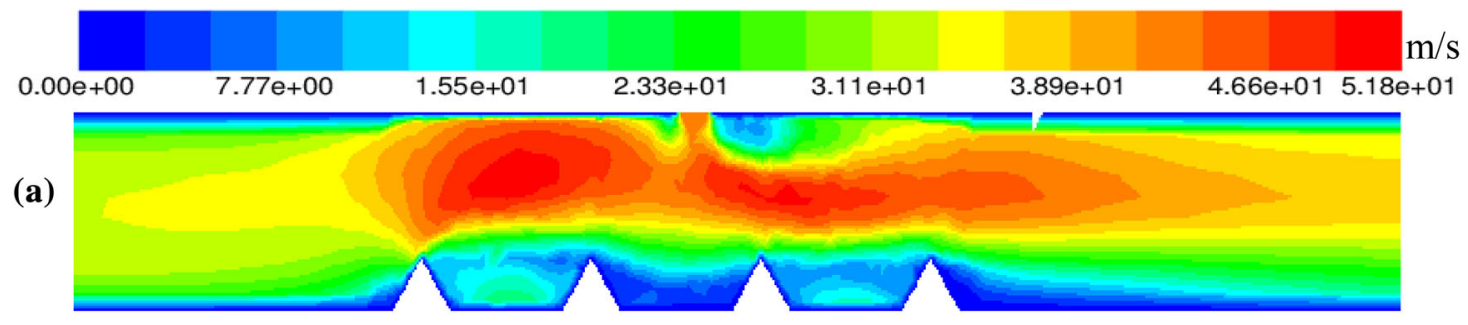

(b)
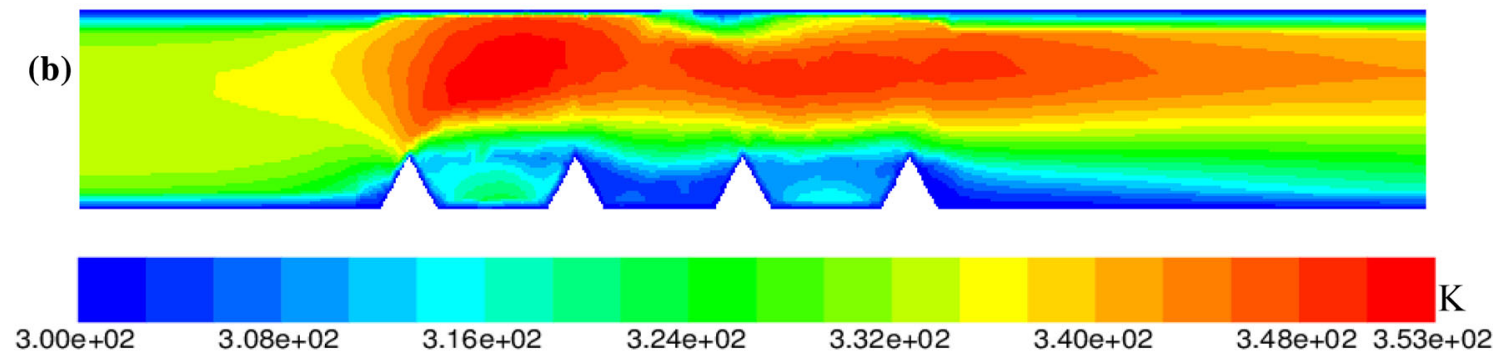

(c)

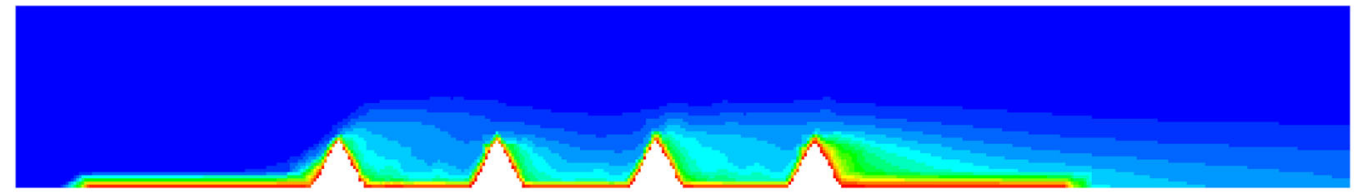

(d)

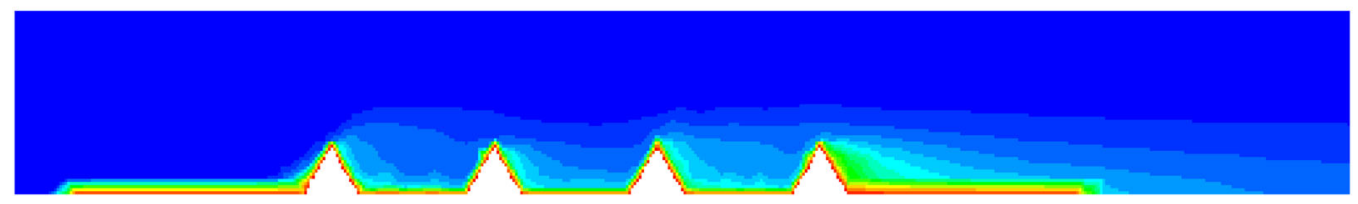

Figure 6. Velocity contours at (a) $\operatorname{Re}_{D h, \text { duct }}=17,827 ;(\mathbf{b}) \operatorname{Re}_{D h, \text { duct }}=53,480$; and temperature contours at (c) $\operatorname{Re}_{D h, \text { duct }}=17,827 ;(\mathbf{d})$ $\operatorname{Re}_{D h, \text { duct }}=53,480$ at $\operatorname{Re}_{D h, n z}=5,135$ and $\operatorname{Pr}=0.7$.

reason for the small increment in the Nusselt number has already been discussed. The enlarged view of the velocity and temperature contours in $\mathrm{X}-\mathrm{Y}$ plane near the protrusions have been shown in figure 6 .
It could be clearly observed that at a low duct Reynolds number (i.e., figure 6(a)), the nozzle fluid is well directed towards the heated surface as compared to that of a high duct Reynolds number case (i.e., figure 6(b)). Despite of 
this fact, the heat transfer with high duct Reynolds number is more because of the increased convection and mixing due to turbulence. Figure 6(c)-(d) shows the temperature contours at $\operatorname{Re}_{\text {Dh,duct }}=17,827$ and 53,480. It is evident that the temperature near the heated surface is more uniform at a higher duct Reynolds number (i.e., figure 6(d)) as compared to a case with low duct Reynolds number (i.e., figure 6(c)). A thinner thermal boundary layer is seen at $\operatorname{Re}_{D h, \text { duct }}=53,480$; whereas it is thicker at $\operatorname{Re}_{\text {Dh,duct }}=17,827$. It is quite obvious that the thinner boundary is capable of dissipating more heat as compared to a thicker boundary layer. Thus, the heat transfer is improved with the duct Reynolds number. The variation of the Nusselt number with the nozzle Reynolds number has been shown in figure 7(a). It has been seen that the Nusselt number variation is almost constant with the nozzle Reynolds number. This is due to the fact that the nozzle Reynolds number used in the present investigation are smaller as compared to the duct the duct Reynolds number so that the nozzle flow is blown off by the main duct flow, and the flow is not able to reach to the protrusions for a direct heat transfer augmentation. At $\operatorname{Re}_{D h, \text { duct }}=17,827$, the Nusselt number has been increased by $11.4 \%$ as the nozzle Reynolds varies in the range of $5,135 \leq \operatorname{Re}_{D h, n z} \leq 12,044$. The increase in heat transfer is further lessened at higher nozzle Reynolds number. For example, in the same range of the nozzle Reynolds number $(5,134-12,044)$ the Nusselt number increases by $4.64 \%, 3.23 \%$ and $2.94 \%$ for the duct Reynolds number of 35,654, 44,567 and 53,480, respectively. The evolution of turbulent kinetic energy (TKE) corresponding to two different nozzle Reynolds numbers (i.e., $\operatorname{Re}_{D h, n z}=5,135$ and 12,044) is illustrated in figure 7(b). For both of these Reynolds number, the variations of TKE with axial distance are almost similar. The TKE in the protruded region only is slightly higher at $\operatorname{Re}_{D h, n z}=$ 12,044 as compared to the value at $\operatorname{Re}_{D h, n z}=5,135$. This

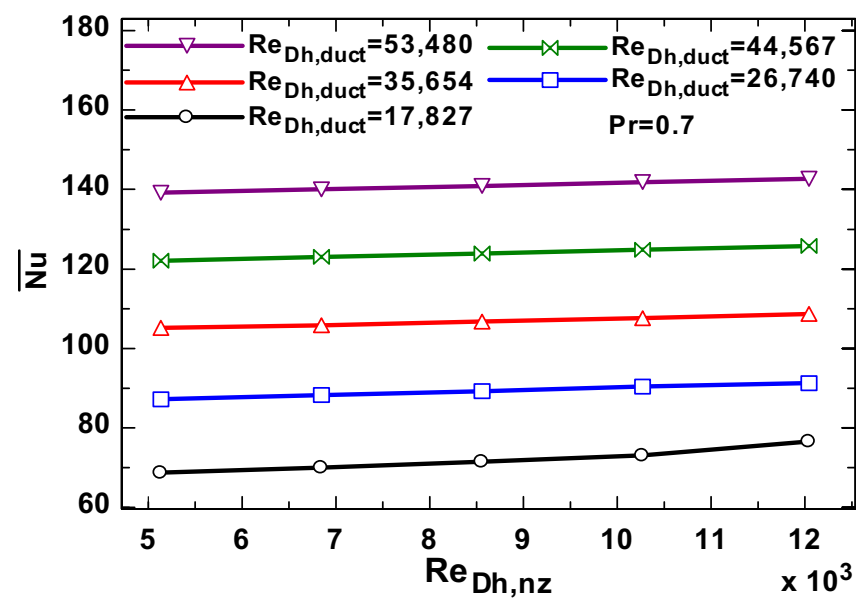

(a) suggests that the nozzle Reynolds number is not one of the important parameters for heat transfer enhancement. For trapezoidal protrusions. Similar observations have been reported by Barik et al [31, 32].

\subsection{Effect of $\operatorname{Pr}$ on $\overline{\mathrm{Nu}}$}

The effect of the Prandtl number on heat transfer has been shown in figure 8(A). At a constant nozzle Reynolds number $\left(\operatorname{Re}_{D h, n z}=8,558\right)$, the duct Reynolds number and the Prandtl number are varied in the ranges of $18,000 \leq \operatorname{Re}_{D h, d u c t} \leq 54,000$ and $0.7 \leq \operatorname{Pr} \leq 12$, respectively. At a particular Prandtl number, the Nusselt number increases monotonously with the duct Reynolds number. For example, at $\operatorname{Pr}=0.7$, the Nusselt number increases $97.2 \%$ for the above range of duct Reynolds number. This increment in the Nusselt number is even more at a higher Prandtl number. For example, at $\operatorname{Pr}=12$, the heat transfer enhancement is about $30 \%$ higher than the value obtained at $\mathrm{Pr}=0.7$. At a high Prandtl number, the gradual steeper slope of the Nusselt number signifies the higher heat transfer rate. The increased heat transfer rate with a higher Prandtl number is attributed to the higher momentum diffusivity as compared to the thermal diffusivity, and as a consequence, the heat diffuses at a faster rate into the bulk fluid. Thus, a high heat transfer rate is obtained at high Prandtl number. The temperature contours for two different Prandtl numbers (i.e., $\operatorname{Pr}=0.7$ and 12) have been shown in figure 8 (B) at duct and nozzle Reynolds numbers of 17,827 and 10,269, respectively. At constant duct and nozzle Reynolds number, it can be observed that thermal boundary layer thickness reduces as Prandtl number is increased. Therefore, a higher Nusselt number is obtained at a high Prandtl number. Also, the thinner thermal boundary layer (i.e., figure 8(B)) formed near the surface protrusion facilitates more heat transfer from the heated plate to the bulk

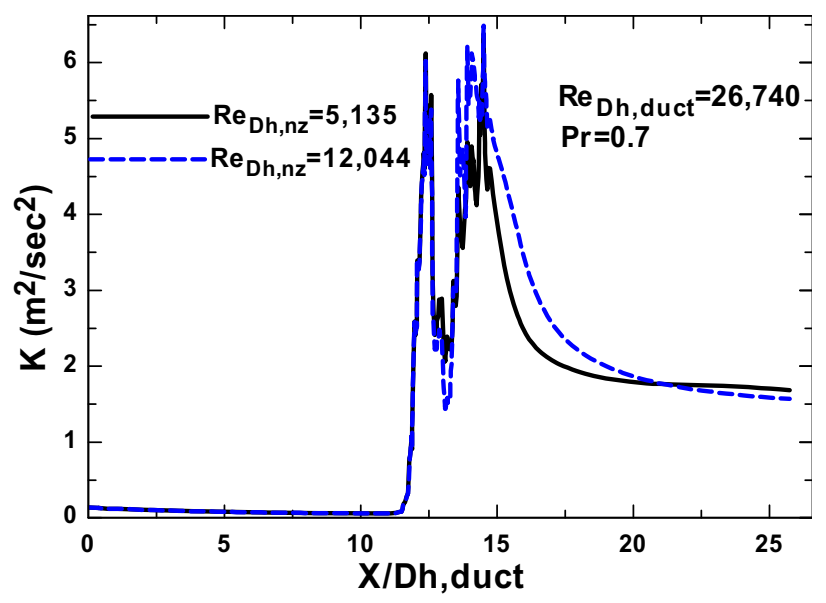

(b)

Figure 7. Variation of (a) $\operatorname{Re}_{D h, n z}$ with $\operatorname{Re}_{D h, n z}$ as the function of $\operatorname{Re}_{D h, d u c t}$. (b) Centreline TKE. 
(a)

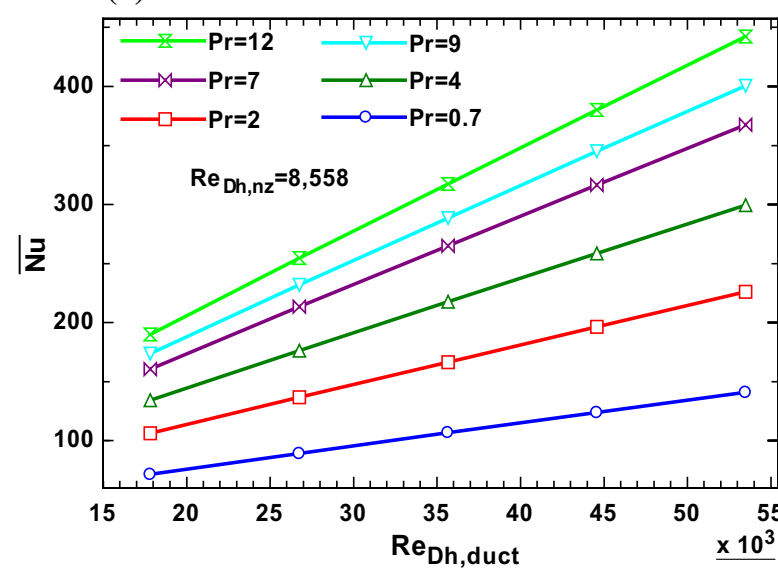

(b)

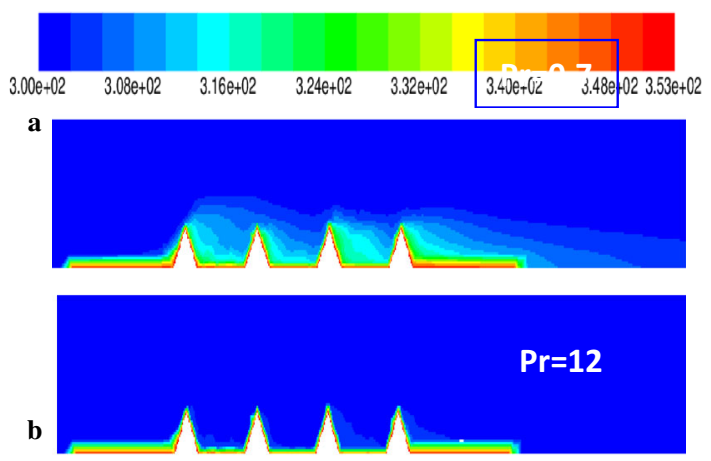

Figure 8. (A) Variation of $\overline{N u}$ with $\operatorname{Re}_{D h, d u c t}$ as a function of Pr; (B) Temperature contours at $\operatorname{Re}_{D h, d u c t}=17,827$ and $\operatorname{Re}_{D h, n z}=10,269$ (a) $\operatorname{Pr}=0.7$; (b) $\operatorname{Pr}=12$.

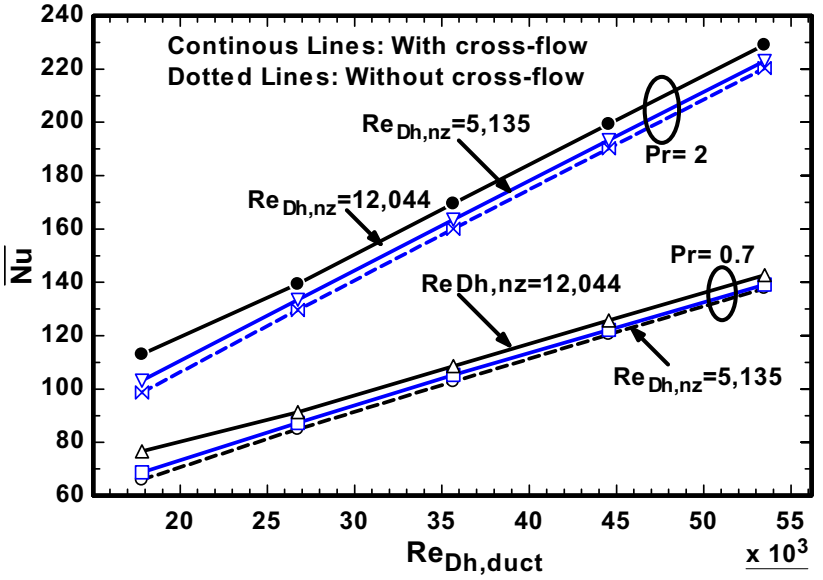

Figure 9. Variation of $\overline{N u}$ with $\operatorname{Re}_{D h, d u c t}$ for with and without cross-flow arrangement.

fluid. As our prime objective is to develop an empirical correlation for Nusselt number in terms of different influencing parameters, we choose to vary the specific heat of the fluid to vary the Prandtl number. This particular parameter has been chosen since it does not appear in the Reynolds number.

\subsection{Comparison of heat transfer with and without cross-flow effects}

For two different Prandtl numbers (i.e., $\operatorname{Pr}=0.7$ and 12), a comparison for heat transfer from the protruded surface without and with the cross-flow arrangements has been depicted in figure 9. The Nueeslt number increases with $\operatorname{Re}_{D h, d u c t}$ for both the arrangements. For a particular $\operatorname{Re}_{D h, n z}$, it has been observed a higher heat transfer for the crossflow arrangement than that of the non cross-flow arrangement. For example, at $\operatorname{Re}_{D h . d u c t}=17,827$ and $\operatorname{Pr}=0.7$, the
Nusselt number for cross-flow arrangement with $\mathrm{Re}_{D h, n z}=$ 5,135 has been increased by $4.25 \%$ as compared to the non cross-flow arrangement.

But for the above case when $\operatorname{Re}_{D h, n z}$ is increased to 12,044 , the Nusselt number is increased by $16.13 \%$. The higher enhancement is attributed to the better penetration of the nozzle fluid. Therefore, it could be claimed that the cross-flow technique is one of the effective techniques for heat transfer augmentation which provides a better mixing of cold and hot fluid, and thereby dissipates a more heat from the heated surface. The mixing of the cold and hot fluids for the cross-flow arrangement can be seen from figures 10(b) and 10(d). The jet after issuing from the nozzle exit can entrain some fluid from the main stream and directs the resultant flow towards the heated surface.

So the heat transfer from the heated surface is improved. When the jet impingent is withdrawn, the main stream after hitting the first protrusion deflects towards the top adiabatic surface (i.e., figures 10(a) and (c)), and the heated surface gets less fresh fluid for heat dissipation. Thus, the heat transfer is reduced for a non cross-flow arrangement. The path lines for these arrangements are shown in figures 10(c)-(d). From the path lines, it is quite clear that the flow is directed more to the heated surface when the jet impingement is deployed. Furthermore, a strong flow recirculation is appeared in the region between two consecutive surface protrusions.

\subsection{Effect of $\operatorname{Re}_{\text {Dh.duct }}$ on $\Delta P$, ff and $P P$}

The pressure drop $(\Delta P)$ variation with $\operatorname{Re}_{D h, d u c t}$ at different $\operatorname{Re}_{D h, n z}$ is illustrated in figure 11(a). It has been noticed that the pressure drop increases with $\operatorname{Re}_{D h, d u c t}$. But this penalty due to jet impingement is not so high in our case. For all $\mathrm{Re}_{D h, n z}$ considered in this study, the pressure drop vs $\operatorname{Re}_{D h, \text { duct }}$ curves show a similar increasing trend with 
(a)

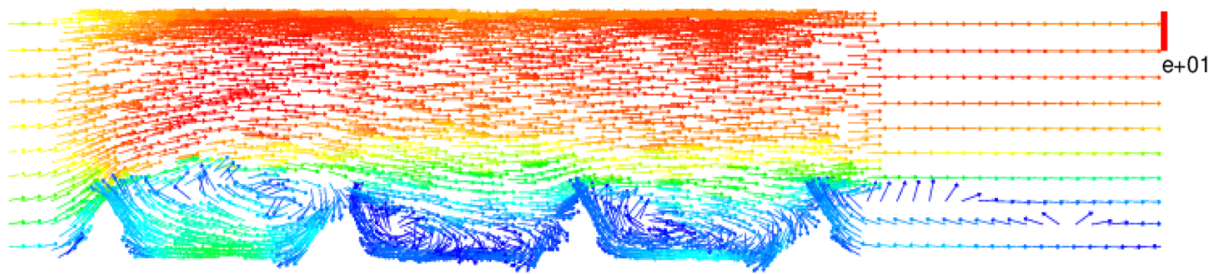

(b)

(c)
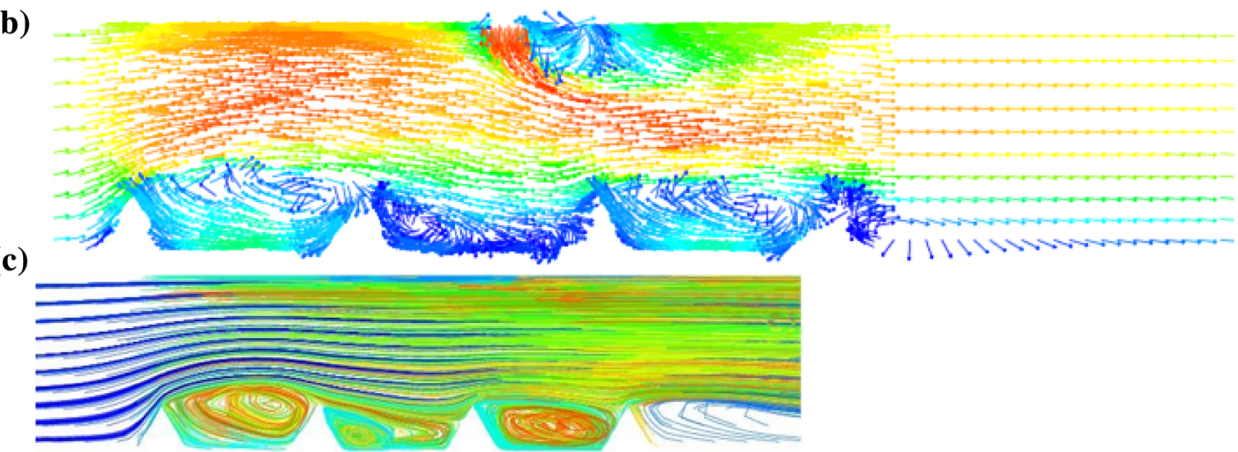

(d)

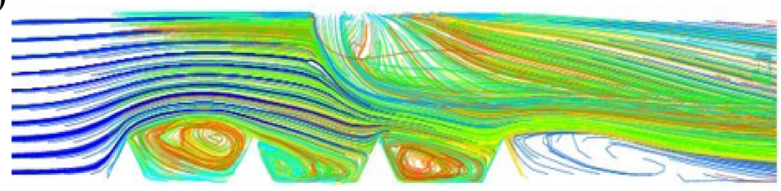

Figure 10. Velocity vectors for (a) $\operatorname{Re}_{D h, \text { duct }}=35,654$; (b) $\operatorname{Re}_{D h, \text { duct }}=35,654$ and $\operatorname{Re}_{D h, n z}=12,044$ Path lines for (c) $\operatorname{Re}_{D h, \text { duct }}=35,654$, (d) $\operatorname{Re}_{D h, \text { duct }}=35,654 \& \operatorname{Re}_{D h, n z}=12,044$.

$\mathrm{Re}_{D h, d u c t}$, which is quite obvious. The pressure drop when non dimensionlized with kinetic energy of the flow give rise to another dimensionless quantity known as friction factor (ff). Physically, the friction factor signifies the amount of energy utilized to overcome the pipe friction out of the total mechanical energy of the flow. Mathematically, it is given as

$$
f f=\frac{(\Delta P / L) D_{h}}{0.5 \rho v^{2}}
$$

Figure 11(b) shows the variation of $f f$ with $\operatorname{Re}_{D h, d u c t}$. From $\operatorname{Re}_{D h, \text { duct }}=17,827-26740$, a sharp decrement in $f f$ has been noticed, and thereafter it decreases asymptotically for other Reynolds number (i.e., 35,654-53,480). When $\mathrm{Re}_{D h \text {,duct }}$ is increased, the denominator of Eq. (23) increases more rapidly as compared to numerator. So $f f$ decreases with $\operatorname{Re}_{\text {Dh,duct }}$. The effect of duct Reynolds number on pumping power has been shown in figure 11(c). The pumping power is calculated as:

$$
P P=\forall \Delta P
$$

In Eq. (24), $\forall$ is the total volume flow rate in the duct which is the sum of the volume flow rates through duct and nozzle inlets. $\Delta P$ is the pressure drop which is the difference between the inlet (duct, nozzle) and outlet pressure. It has been revealed from figure 11(c) that the pumping power increases with $\operatorname{Re}_{D h, \text { duct }}$.
For example, at $\operatorname{Re}_{D h \text {.duct }}=5,135$, the pumping power increases from $0.51 \mathrm{~W}$ to $10.08 \mathrm{~W}$ when the duct Reynolds number increases from 17,827 to 53,480 . But the pumping power increases marginally with $\mathrm{Re}_{D h, n z}$, which suggests a nominal penalty for pumping power when the jet is deployed to enhance heat transfer. With the use of an impinging jet, the higher pumping power is because of the combined effects of the increased pressure drop and the high volume flow rate. In our present study, the pumping powers required to operate the system to cool the heated surface are not much higher and these pumping powers can easily be maintained.

\subsection{Correlation for Nusselt number}

Our prime objective of this study is to develop an empirical correlation for the Nusselt number in terms of the pertinent model parameters, which could be useful for practical engineering applications. So the functional dependency of the Nusselt number on the model parameters is expressed as:

$$
\overline{N u}=f\left(\operatorname{Re}_{D h, d u c t}, \operatorname{Re}_{D h, n z}, \operatorname{Pr}\right)
$$

It is worth to mention here that the distance between two consecutive protrusions, the number and height of each of protrusion are kept constant. In our future research, we will vary all these parameters along with perforations (i.e., fluid 


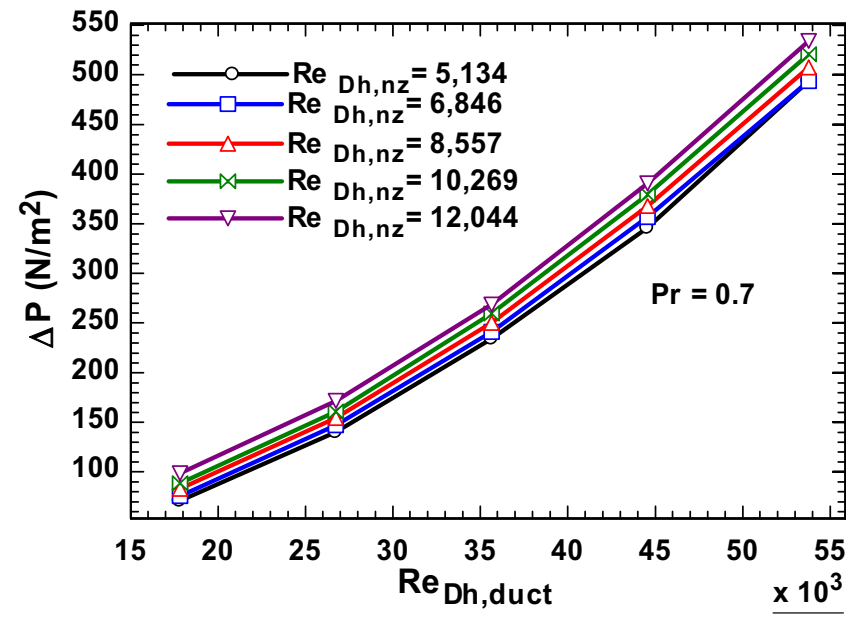

(a)

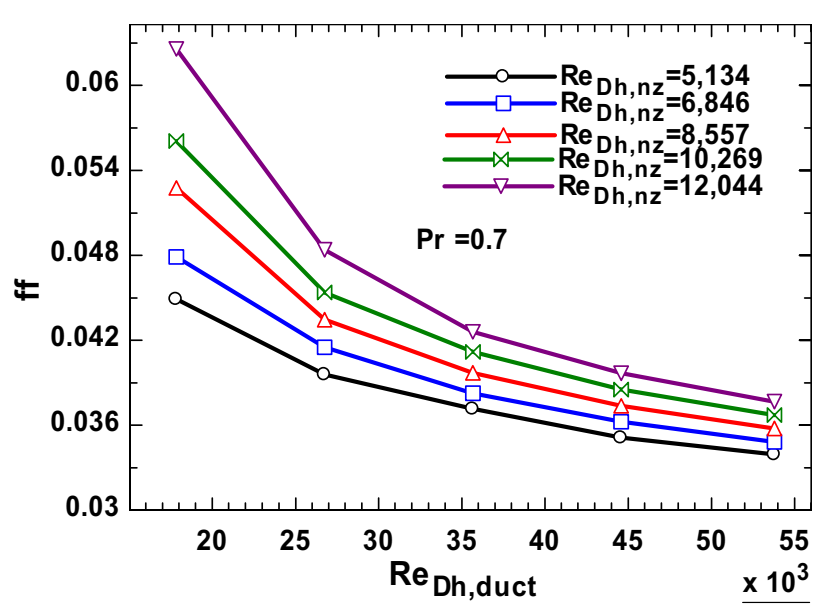

(b)

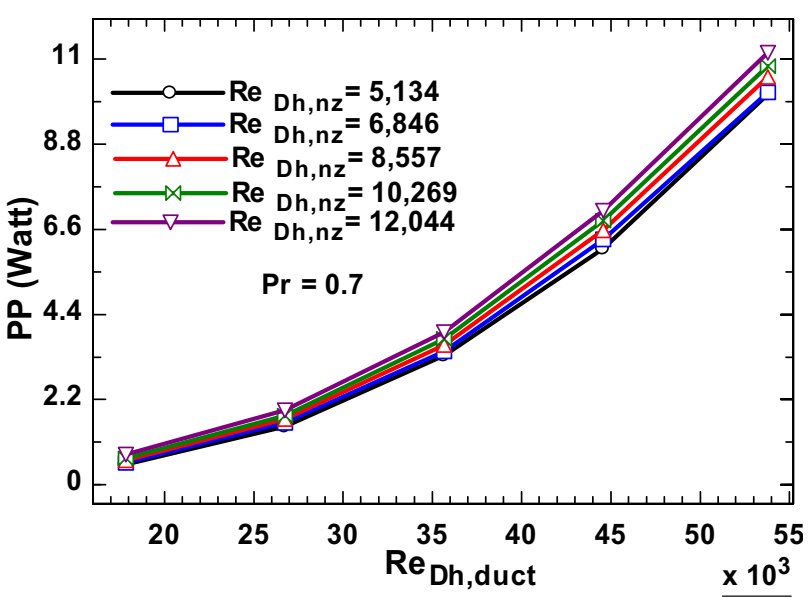

(c)

Figure 11. Variations of (a) pressure drop $(\Delta P)$; (b) friction factor (ff); (c) pumping power $(P P)$ with $\operatorname{Re}_{D h, d u c t}$.

passages through the solid protrusions) cut through the protrusions. Extensive numerical computations have been executed to collect the data for Nusselt number by varying each of the influencing parameter in wide ranges. Nonlinear regression analysis has been carried out in POLYMATH to develop the correlation for the Nusselt number. The Lvenberg-Marquardt (L-M) method with appropriate initial guess value has been employed to start the solution iteratively in order to obtain the correlation coefficients. For the sake of simplicity in understanding, a small description on the LM method has been incorporated. Basically, the LM method is a non-linear least square method aimed at minimization of an objective function fitted from its model parameters/control parameters employing two different minimization techniques, such as the gradient decent method and the Gauss-Newton method. The LM method behaves like a gradient decent method when the parameters are away from its optimal value, and when the parameters are close to the optimal value it acts as Gauss-Newton method. Although the objective function in gradient decent method changes quickly after changing the value of the parameters, it is usually very slow method as it takes a zigzag path for getting the optimal solution.

The Gauss-Newton method is relatively faster than the later method. But the Gauss-Newton method of minimization is prone to the parameter evaporation (i.e., the parameters returned by the algorithm may be far away from the real value).The $\mathrm{L}-\mathrm{M}$ method takes the advantages of the above minimization techniques [44, 45], and hence, it is better than the other one. Thus, we choose to use L-M method to develop our correlation. The CFD data are collected from the simulations and are non-linearly regressed by choosing the appropriate initial guess values. The iterations are carried out repeatedly and initial guesses have been readjusted until the goodness of the fit the data points becomes near to unity. In the present case, we took 225 data points in our non-linear analysis, and we obtained a correlation for Nusselt number which may be accepted for the engineering point of view. The appropriate correlation coefficients have been obtained from the non-linear regression analysis. After carrying out the non-linear 


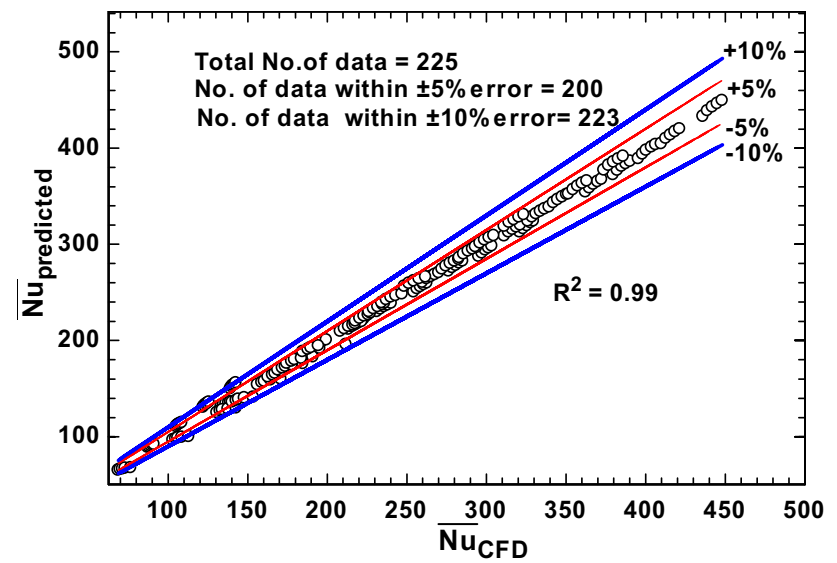

Figure 12. Comparison of CFD and predicted values of $\overline{N u}$ (Parity plot).

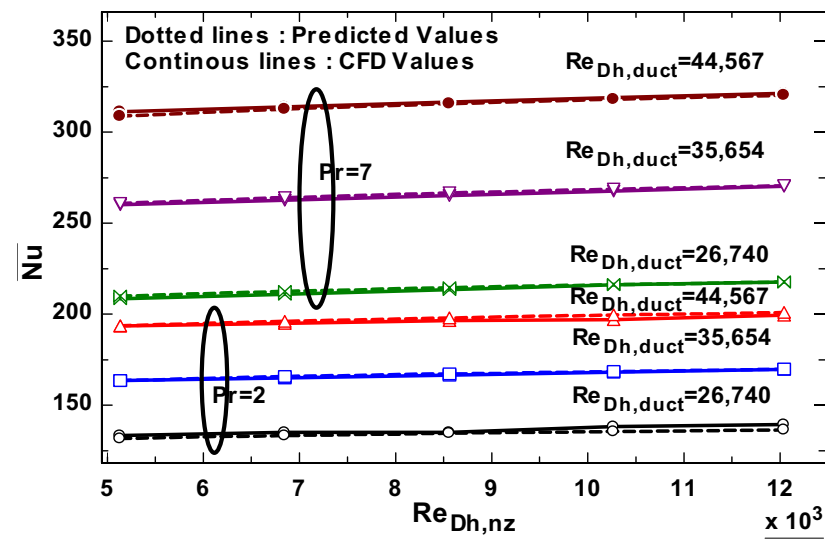

Figure 13. Comparison for the CFD and predicted values of $\overline{N u}$ vs $\operatorname{Re}_{D h, n z}$.

regression analysis, the empirical equation developed for Nusselt number is given as:

$$
\overline{N u}=0.312 \times\left(\operatorname{Re}_{D h, d u c t}\right)^{0.75} \times\left(\operatorname{Re}_{D h, n z}\right)^{0.04} \operatorname{Pr}
$$

The above correlation is valid in the following ranges: $17,827 \leq \operatorname{Re}_{D h, \text { duct }} \leq 53,480, \quad 5,135 \leq \operatorname{Re}_{D h, n z} \leq 12,044$ and $0.7 \leq \operatorname{Pr} \leq 12$.

Figure 12 shows the comparison between the CFD values and predicted values of Nusselt number. It can be seen that the predicted Nusselt number matches well with the CFD Nusselt number. Most of the data points lie in error band $\pm 5 \%$ which is very good for any correlation equation.

\subsection{Some sample plots for comparison of the CFD and the predicted values}

The Nusselt number obtained from the correlation and the CFD computations are compared with each other by varying some of the influencing parameters. These comparisons are shown in figures 13-14 for three different Prandtl

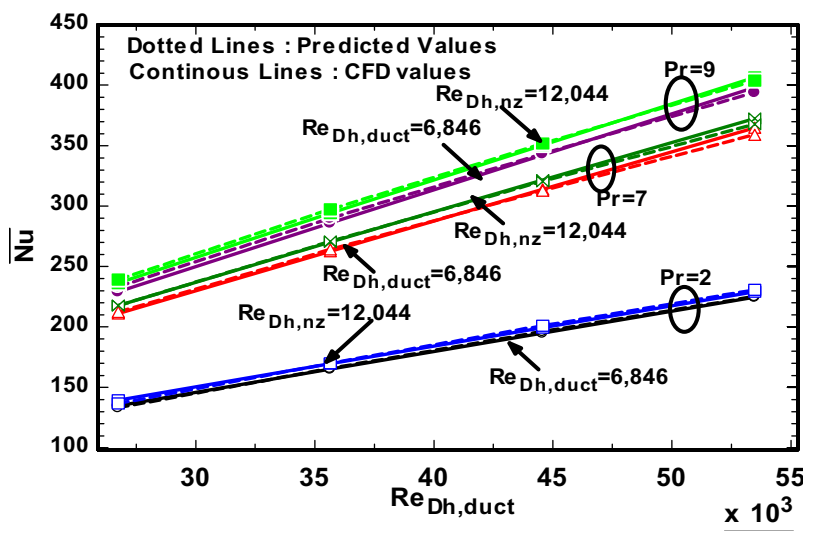

Figure 14. Comparison for the CFD and predicted values of $\overline{\mathrm{Nu}}$ vs $\operatorname{Re}_{\text {Dh,duct }}$.

numbers $(\operatorname{Pr}=2,7$ and 9). It can be seen that both the Nusselt numbers match well with each other. The error between the predicted and CFD values is very less. The variation of the Nusselt number with nozzle Reynolds number has been shown in figure 13 .

For a particular $\operatorname{Re}_{D h, d u c t}$, it is observed that the Nusselt number remains constant over the entire range of $\operatorname{Re}_{D h, n z}$. At a high duct Reynolds number, the jet is carried away with the main flow without reaching to the heated surface. The jet may not actively participate in the heat transfer enhancement. However, it improves the turbulence which indirectly improves the heat transfer. Also, the low momentum fluid from the nozzle is blown with the high momentum duct flow. Therefore, the plots remain flat with $\operatorname{Re}_{D h, n z}$. Figure 12 shows the comparative variations in Nusselt number obtained from the correlation and CFD computations. A perfect match between the correlation and CFD computations has been seen. For example, at $\operatorname{Pr}=2$ and $\operatorname{Re}_{D h, n z}=12,044$, the differences between the correlation and CFD values of $\overline{N u}$ are found to be $1.20 \%, 0.37 \%$, $0.61 \%$, and $0.23 \%$, respectively at $\mathrm{Re}_{D h \text {, duct }}=26720$, 35654,44567 and 53480.

\section{Conclusions}

The heat transfer enhancement from a rectangular duct with triangular non-conducting protrusions with and without the jet impingement has been studied numerically in a threedimensional computational domain employing finite volume method of ANSYS Fluent 16. The non-linear governing differential equations have been solved iteratively imposing appropriate boundary conditions. Careful and rigorous simulations have been carried out to collect the data for the Nusselt number over wide range of the operating parameters. The CFD data are non-linearly regressed to develop the heat transfer correlation. Following conclusions are drawn from the present study: 
(i) The duct Reynolds number is found to be one of the influencing parameters for heat transfer enhancement from a hot protruded surface. Although it has been obtained that the nozzle Reynolds number does not improve heat transfer as effectively as the duct Reynolds number, it indirectly improves the heat transfer by promoting the turbulence level in the flow domain and the gap between the protrusions.

(ii) The Nusselt number is also a strong function of the Prandtl number of the fluid. At a high Prandtl number the kinematic diffusivity of the fluid has been increased making it easier for the heat removal from the protruded surface.

(iii) The functional dependency of the Nusselt number on the influencing parameters has been formulated in the form of a correlation equation fitted through a non-linear regression analysis of CFD data using the Lvenberg-Marquardt algorithm. The Nusselt number predicted from the correlation matches well with the Nusselt number computed from the CFD simulations.

\section{Acknowledgements}

This work was supported by the Science and Technology Department, Govt. of Odisha, India through research grant no: 27562800512017/20/1255/ST, Letter No: 1056/CET.

\section{List of symbols}

$\begin{array}{ll}A_{\text {total }} & \text { total area }\left(\mathrm{m}^{2}\right) \\ A_{b w} & \text { hot wall area }\left(\mathrm{m}^{2}\right) \\ A_{P} & \text { area of protruded surface }\left(\mathrm{m}^{2}\right) \\ \mathrm{D} & \text { diameter of circular jet }(\mathrm{m}) \\ f f & \text { friction factor } \\ \mathrm{H} & \text { distance between the jet and circular plate }(\mathrm{m}) \\ \mathrm{I} & \text { turbulent intensity } \\ k & \text { turbulent kinetic energy }(\mathrm{TKE})\left(\mathrm{m}^{2} / \mathrm{s}^{2}\right) \\ \lambda & \text { thermal conductivity }(\mathrm{W} / \mathrm{m}-\mathrm{K}) \\ \overline{N u} & \text { average Nusselt number } \\ \omega & \text { rate of dissipation of TKE } \\ \mathrm{Pr} & \text { Prandtl number } \\ \operatorname{Re}_{\operatorname{Re}_{D h, d u c t}} & \text { Reynolds number } \\ \operatorname{Re}_{D h, n z} & \text { nozzle Reynolds number }\end{array}$

\section{References}

[1] Fabbri M, Jiang S and Dhir V K 2005 A comparative study of cooling of high power density electronics using sprays and micro jets. J. Heat Transf. 127: 38-48
[2] Han B and Goldstein R J 2001 Jet-impingement heat transfer in gas turbine systems. Ann. N. Y. Acad. Sci. 934: 147-161

[3] Polat S 1993 Heat and mass transfer in impingement drying. Dry. Technol. 11: 1147-1176

[4] Martin H 1977 Heat and mass transfer between impinging gas jets and solid surfaces. Adv. Heat Transf. 13: 1-60

[5] Bahaidarah H M S 2016 Experimental performance evaluation and modelling of jet impingement cooling for thermal management of photovoltaics. Solar Energy 135: 605-617

[6] Nobari A H, Prodanovic V and Militzer M 2016 Heat transfer of a stationary steel plate during water jet impingement cooling. Int. J. Heat Mass Transf. 101: 1138-1150

[7] Yu P, Zhu K, Shi Q, Yuan N and Ding J 2017 Transient heat transfer characteristics of small jet impingement on hightemperature flat plate. Int. J. Heat Mass Transf. 114: 981-991

[8] Guoneng L, Zhihua X, Youqu Z, Wenwen G and Cong D 2016 Experimental study on convective heat transfer from a rectangular flat plate by multiple impinging jets in laminar cross flow. Int. J. Therm. Sci. 108: 123-131

[9] Wae-hayee M, Tekasakul P, Eiamsa-ard S and Chayut N 2014 Effect of cross flow and heat transfer characteristics of impinging jet with low jet-to-plate distance. J. Mech. Sci. Technol. 28: 2909-2917

[10] Modak M, Garg K, Srinivasan S and Sahu S K 2017 Theoretical and experimental study on heat transfer characteristics of normally impinging two dimensional jets on a hot surface. Int. J. Therm. Sci. 112: 174-187

[11] Yao S, Guo Y, Jiang N and Liu J 2015 An experimental study of turbulent jet impinging on a flat surface. Int. J. Heat Mass Transf. 83: 820-832

[12] Trinh X T, Fenot M and Dorignac E 2016 The effect of nozzle geometry on local convective heat transfer to unconfined impinging air jets. Exp. Therm. Fluid Sci. 70: $1-16$

[13] Boulemtafes-Boukadoum A and Benzaoui A 2014 CFD based analysis of heat transfer enhancement in solar air heater provided with transverse rectangular ribs. Energy Proc. 50: 761-772

[14] Yadav A S and Bhagoria J L 2014 A numerical investigation of square sectioned transverse rib roughened solar air heater. Int. J. Therm. Sci. 79: 111-131

[15] Jin D, Zhang M, Wang P and Xu S 2015 Numerical investigation of heat transfer and fluid flow in a solar air heater duct with multi $\mathrm{V}$-shaped ribs on the absorber plate. Energy 89: $178-190$

[16] Behnampour A, Akbari O A, Safaei M R, Ghavami M, Marzban A, Shabani G A S, Zarringhalam M and Mashayekhi M R 2017 Analysis of heat transfer and nanofluid fluid flow in microchannels with trapezoidal, rectangular and triangular shaped ribs. Phys. E: Low-Dimens. Syst. Nanostruct. 91: 15-31

[17] Zhang D, Qu H, Lan J, Chen J and Xie Y 2013 Flow and heat transfer characteristics of a single jet impinging on protrusion surface. Int. J. Heat Mass Transf. 58: 18-28

[18] Rao Y, Chen P and Wan C 2016 Experimental and Numerical investigation of impingement heat transfer on the surface with micro W-shaped ribs. Int. J. Heat Mass Transf. 93: 683-694

[19] Gawande V B, Dhoble A S, Zodpe D B and Chamoli S 2016 Experimental and CFD investigation of convection heat 
transfer in solar air heater with reverse L-shaped ribs. Solar Energy 131: 275-295

[20] Pandit J, Thompson M, Ekkad S V and Huxtable S T 2014 Effect of pin fin to channel height ratio and pin fin geometry on heat transfer performance for flow in rectangular channels. Int. J. Heat Mass Transf. 77: 359-368

[21] Katkhaw N, Vorayos N, Kiatsiriroat T, Khunatorn Y, Bunturat D and Nuntaphan A 2014 Heat transfer behaviour of flat plate having $45^{\circ}$ ellipsoidal dimpled surfaces. Case Stud. Therm. Eng. 2: 67-74

[22] Katkhaw N, Vorayos N, Kiatsiriroat T and Nuntaphan A 2016 Heat transfer behaviour of flat plate having spherical dimpled surfaces. Case Stud. Therm. Eng. 8: 370-377

[23] Zhang F, Wang X and Li J 2017 Flow and heat transfer characteristics in rectangular channels using combination of convex-dimples with grooves. Appl. Therm. Eng. 113: 926-936

[24] Leontiev A I, Kiselev N A, Vinogradov Y A, Strongin M M, Zditovets A G and Burtsev S A 2017 Experimental investigation of heat transfer and drag on surfaces coated with dimples of different shape. Int. J. Therm. Sci. 118: 152-167

[25] Rao Y, Li B and Feng Y 2015 Heat transfer of turbulent flow over surfaces with spherical dimples and teardrop dimples. Exp. Therm. Fluid Sci. 61:201-209

[26] Park J S, Jo Y H and Kwak J S 2016 Heat transfer in a rectangular duct with perforated blockages and dimpled side walls. Int. J. Heat Mass Transf. 97: 224-231

[27] Sahel D and Benzeguir R 2017 Thermal characteristics in solar air heater fitted with plate baffles and heating corrugated surface. Energy Proc. 139: 307-314

[28] Li J-L, Tang H-W and Yang Y-T 2018 Numerical simulation and thermal performance optimization of turbulent flow in a channel with multi $\mathrm{V}$-shaped baffles. Int. Commun. Heat Mass Transf. 92: 39-50

[29] Kumar P, Kumar A, Chamoli S and Kumar M 2016 Experimental investigation of heat transfer enhancement and fluid flow characteristics in a protruded surface heat exchanger tube. Exp. Therm. Fluid Sci. 71: 42-51

[30] Gilani S E, Al-Kayiem H H, Woldemicheal D E and Gilani S I 2017 Performance enhancement of free convective solar air heater by pin protrusions on the absorber. Solar Energy 151: $173-185$

[31] Barik A K, Mukherjee A and Patro P 2015 Heat transfer enhancement from a small rectangular channel with different surface protrusions by a turbulent cross flow jet. Int. J. Therm. Sci. 98: 32-41
[32] Barik A K, Rout S and Mukherjee A 2016 Numerical investigation of heat transfer enhancement from a protruded surface by cross flow jet using $\mathrm{Al}_{2} \mathrm{O}_{3}$-water nanofluid. Int . J. Heat Mass Transf. 101: 550-561

[33] Menter F R 1994 Two-equation eddy-viscosity turbulence models for engineering applications. AIAA J. 32: 1598-1605

[34] Kumar R and Dewan A 2014 URANS computations with buoyancy corrected turbulence models for turbulent thermal plume. Int. J. Heat Mass Transf. 72: 680-689

[35] Srivastava P, Dewan A and Bajpai J K 2017 Flow and heat transfer characteristics in convergent-divergent shaped microchannel with ribs and cavities. Int. J. Heat Technol. 35: 863-873

[36] Salim S M, Ong K C and Chiah S C 2011 Comparison of RANS, URANS and LES in prediction of air flow and pollutant dispersion. In: Proceedings of the World Congress on Engineering and Computer Science Vol II, WCECS 2011, October 19-21, San Francisco, USA

[37] Yang Z 2014 Assessment of unsteady-RANS approach against steady-RANS approach for predicting twin impinging jets in a cross-flow. Cogent Eng., https://doi.org/10.1080/ 23311916.2014.936995

[38] Barth T J and Jespersen D C 1989 The design and application of upwind schemes on unstructured meshes. AIAA Paper No. 89-0366

[39] Patankar S V 1980 Numerical Heat Transfer and Fluid Flow. Philadelphia: Hemisphere Publishing Corporation

[40] Launder B E and Spalding D B 1974 The numerical computation of turbulent flows. Comput. Methods Appl. Mech. Eng. 3: 269-289

[41] Markal B and Aydin O 2018 Experimental investigation of coaxial impinging air jets. Appl. Therm. Eng. 141: $1120-1130$

[42] Choo K S and Kim S J 2010 Comparison of thermal characteristics of confined and unconfined impinging jets. Int. J. Heat Mass Transf. 53: 3366-3371

[43] Lytle D and Webb B W 1994 Air jet impingement heat transfer at low nozzle-plate spacing. Int. J. Heat Mass Transf. 37: $1687-1697$

[44] Marquardt D W 1963 An algorithm for least-squares estimation of nonlinear parameters. J. Soc. Ind. Appl. Math. 11(2): 431-441

[45] Transtrum M K, Machta B B and Sethna J P 2010 Why are nonlinear fits to data so challenging? Phys. Rev. Lett. 104: 060201 